\title{
Natureza do caso ergativo e dativo em línguas Jê e suas consequências para a Teoria de Caso
}

\author{
The nature of ergative and dative cases in jê languages \\ and its consequences to case theory
}

\author{
Fábio Bonfim Duarte* \\ Universidade Federal de Minas Gerais \\ Isadora Barcelos Silva** \\ Universidade Federal de Minas Gerais
}

\begin{abstract}
This paper shows that there exists a strong connection between Case evaluation and the assignment of the [AGENT] and [EXPERIENCER] theta roles to the external arguments of unergative and transitive verbs in languages such as Apinajé, Apãniekrá, Parkatêjê, Xavante and Maxacali. Additionally, we investigate whether the ergative Case and the dative Case in these languages correspond to inherent Case or to structural Case. We assume that these Cases are structurally valued by the functional pospositions [mã] and [te] in the vP domain. The strongest evidence that favors this analysis comes from the fact that the functional head $\mathrm{T}^{\circ}$ does not enter in the derivation with abstract Case to value. Furthermore, the distribution of the pospositions [mã] and [te] clearly demonstrates that they behave as adpositions in the sense that they can co-occur with pronominal prefixes and can come enclitic to oblique phrases that appear in passive constructions.
\end{abstract}




\section{Keywords}

Jê languages, Ergativity, Dative and ergative Cases, Light verb, Theta role.

\section{Resumo}

Este artigo mostra que há forte conexão entre valoração de Caso e atribuição dos papéis theta [AGENTE] e [EXPERIENCIADOR] a argumentos externos de verbos transitivos e inergativos em línguas como Apinajé, Apãniekra, Parkatêjê, Xavante e Maxacali. Adicionalmente, averiguamos se os Casos ergativo e dativo nessas línguas correspondem, ao final de contas, a Caso inerente ou a Caso estrutural. Assumimos que esses Casos são estruturalmente valorados pelas posposições funcionais [te] e [mã] no domínio vP. A forte evidência a favor desta hipótese surge do fato de que o núcleo funcional $\mathrm{T}^{0}$ não entra na derivação com Caso abstrato a valorar. Ademais, a distribuição das partículas [mã] e [te] claramente demonstra que elas se comportam como adposições, pois podem coocorrer com os prefixos pronominais e podem vir enclíticas a sintagmas oblíquos que figuram nas construções passivas.

\section{Palavras-chave}

Línguas Jê, Ergatividade, Casos ergativo e dativo, Verbo leve, Papel theta. 


\section{Introdução}

$\mathrm{U}$

m dos objetivos deste artigo é discutir se o Caso ergativo realizado por meio da posposição [te] em línguas do tronco linguístico Macro-Jê equivale mesmo a Caso inerente ou se, ao contrário, corresponde a Caso estrutural. Outro objetivo é alcançar uma resposta satisfatória e unificada para as seguintes questões:

(1) Os papéis theta [AGENTE] e [EXPERIENCIADOR] mantêm sempre relação biunívoca com os Casos ergativo e dativo?

(2) Casos ergativo e dativo de AEs correspondem, ao final de contas, a Caso inerente ou a Caso estrutural?

(3) Qual o estatuto das posposições [te] e [mã]?

Para responder às indagações acima, apresentamos, nas próximas seções, o aporte teórico no qual esta pesquisa se baseia e a análise dos dados empíricos. Pelo momento, focalizaremos cinco línguas do tronco linguístico Macro-Jê, a saber: da família Jê, analisamos o Apãniekra, o Apinajé, o Parkatejêe o Xavante; eda família Maxacali, avaliamos o Maxacali. Uma pesquisa futura deverá, evidentemente, coletar mais dados de outras línguas para dar sustentação à nossa análise.

O artigo está organizado em quatro seções. Na seção 1, traçamos o quadro teórico em que se desenvolve nossa discussão, delineando as diferenças entre Caso estrutural e inerente, em especial, a íntima correlação do Caso inerente com os papéis theta [+AGENTE] e [+EXPERENCIADOR]. Na seção 2, por meio dos dados da língua Maxacali demonstramos que a realização do Caso ergativo pela posposição [te] está diretamente correlacionada com o fato de os sujeitos receberem papel theta [+AGENTE]. Pontuamos, todavia, que essa relação não é biunívoca e sistemática, uma vez que a posposição [te] também se estende a argumentos externos de verbos psicológicos naquela língua. Na seção 3, analisamos o padrão de Caso exibido pelas línguas Apãniekra, Apinajé e 
Parkatejê, em que se observa a biunivocidade entre o Caso ergativo e o Caso dativo, respectivamente realizados pelas posposições [te] e [mã], e a atribuição dos papéis temáticos [+AGENTE] e [+EXPERIENCIADOR]. Na seção 4, mostramos que, nas línguas Jê, [te] e [mã] têm o estatuto de posposições funcionais que encabeçam sintagmas posposicionais juntados na posição de Spec-vP, cuja função sintática é apenas valorar Caso estrutural oblíquo dos DPs que ocupam a posição de seus complementos. Na seção 5, lançamos a hipótese de que as posposições [mã] e [te], apesar de valorarem Caso estrutural, não participam da atribuição do papel temático a seus complementos, já que tais argumentos são acarretados semanticamente pelo verbo leve. Por fim, na seção 6, apresentamos nossas conclusões. Comecemos então com discussão teórica sobre a distinção entre Caso estrutural e Caso inerente.

\section{Da diferença entre Caso estrutural e Caso inerente}

Nos estudos sobre a teoria de Caso, considera-se que os sistemas nominativos emergem quando há o alinhamento morfossintático entre o Caso do sujeito dos verbos intransitivos com o Caso do sujeito do verbo transitivo. Em termos mais técnicos, podemos dizer que esse alinhamento pode ser tratado, formalmente, como sendo o reflexo da valoração do Caso do sujeito dos verbos transitivos e intransitivos pelo núcleo $\mathrm{T}^{\circ}$. Em geral, este núcleo poderá valorar o Caso do sujeito desses verbos se a oração for finita e se o núcleo $\mathrm{T}^{\circ}$ entrar na derivação sintática com traço de Caso nominativo a valorar. A valoração desse Caso dá-se por meio de uma operação AGREE $^{1}$ que ocorre entre o núcleo $\mathrm{T}^{\circ}$ e o DP alvo. Essa operação ocorre essencialmente por meio de uma relação assimétrica que se dá entre uma sonda,(Probe), e o DP alvo (Goal). Em síntese, a operação AGREE será o mecanismo sintático que permitirá a valoração dos traços ininterpretáveis, seja da sonda, seja do alvo. A valoração dá-se, então, quando os traços ininterpretáveis $[u F]$ se combinam com os traços interpretáveis [iF]. Após esse mecanismo de valoração, ocorre a unificação dos valores dos traços, de modo que os traços ininterpretáveis são valorados e removidos, situação que permitirá que a derivação continue e seja enviada a Spell-Out. Adaptando essa noção para o mecanismo que permite a valoração dos traços de Caso estrutural, podemos afirmar que o DP alvo pode conter um traço ininterpretável de Caso que precisa ser valorado pelo núcleo $\mathrm{T}^{\circ}$, quando este 
núcleo entra na derivação especificado com nominativo a valorar. Esse núcleo pode, por sua vez, conter também traços ininterpretáveis, como os traços-phi e o traço EPP, os quais devem também ser valorados. Em geral, os traços-phi são valorados quando há compartilhamento desses traços com os traços-phi interpretáveis de um DP alvo que esteja no domínio de c-comando do núcleo Tº Por sua vez, o traço EPP é valorado ou pela inserção de um expletivo na posição de Spec-TP ou por meio da elevação do DP, que recebe Caso nominativo, para essa posição. A operação de valoração de Caso nominativo pode dar-se à distância, na relação NúCLEO-COMPLEMENTO, ou localmente, na relação SPECNúCLEO, conforme mostram as configurações sintáticas a seguir.

(4) Valoração de Caso Nominativo na relação spec-núcleo

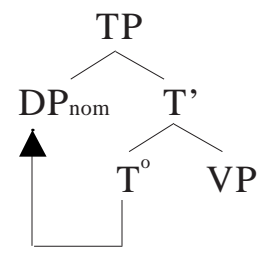

(5) Valoração de Caso Nominativo à distância

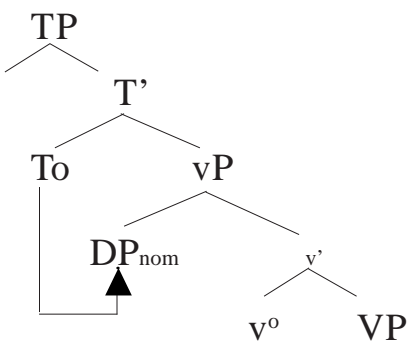

Note que as operações sintáticas acima têm como consequência a emergência de um sistema nominativo, o qual é encontrado, por exemplo, em línguas como o inglês e o português. Todavia, nestas línguas, quando o núcleo $\mathrm{T}^{\circ}$ entra na derivação sem Caso estrutural a valorar, como ocorre, por exemplo, nas orações não finitas do inglês, o sujeito do verbo (transitivo ou intransitivo) precisará ter seu Caso abstrato valorado excepcionalmente por outro núcleo, de modo a não violar o filtro de Caso. Um desses núcleos pode ser o núcleo v vo de 
uma oração matriz. Note que, em tais contextos, o Caso do sujeito corresponderá ao acusativo, conforme ilustra o exemplo a seguir.

(6a) We believed [Zeus to be omnipotent].

(6b) No one excepted [Agamemnon to win].

Uma evidência a favor de que o Caso do sujeito da oração encaixada é realmente o acusativo pode ser notada quando substituímos o sujeito por pronomes. Nessas situações, os pronominais que emergem na posição de sujeito equivalem às formas acusativas e não às formas nominativas, conforme mostram os exemplos a seguir.

(7a) We $\left[_{\mathrm{V}}\right.$ believed $\left[_{\mathrm{TP}}\right.$ him to be omnipotent].

(7b) No one $\left[_{V}\right.$ excepted $\left[_{\mathrm{TP}}\right.$ him to win].

Veja que a razão por que o sujeito das sentenças acima vem com o Caso acusativo está diretamente conectada com as propriedades morfossintáticas do núcleo $\mathrm{T}^{\circ}$ da oração encaixada. Mais precisamente, como esse núcleo não entra na derivação com Caso nominativo a valorar e como a oração é não finita, o DP sujeito da oração encaixada virá com o Caso acusativo, e não com o Caso nominativo. Note que esses dois Casos são estruturais pelo fato de não estarem conectados com um núcleo que lhes atribui papel temático e pelo fato de sua valoração ocorrer por meio de uma relação estrutural envolvendo, em geral, o domínio funcional da sentença.

Todavia, os sistemas ergativos diferem substancialmente dos sistemas nominativos pelo fato de o sujeito de verbos transitivos, em geral os que denotam ação, vir marcado com o Caso ergativo, e não com o Caso nominativo. Uma das possíveis razões por que o Caso nominativo não está disponível ao sujeito dos verbos de ação nessas configurações sintáticas pode estar diretamente conectada com os seguintes fatores gramaticais: ${ }^{2}$

(i) a íntima relação que há entre a atribuição do papel temático [AGENTE] e o Caso do sujeito dos verbos de ação;

(ii) a natureza morfossintática do núcleo $\mathrm{T}^{\circ}$ nas sentenças não finitas;

(iii) o fato de o DP marcado com Caso ergativo vir acompanhado por posposições de natureza funcional. 
Parece que a íntima relação entre a atribuição de papel temático de agente e o Caso ergativo do sujeito dos verbos de ação não pode ser considerada uma razão para o Caso nominativo não estar disponível, mas apenas uma característica do Caso inerente. Nos sistemas nominativo/acusativos os sujeitos agentes, em geral, vão receber o Caso nominativo, quando o núcleo T se encontra ativado. Mas também podem receber Caso acusativo, como demonstrado anteriormente nos contextos de marcação excepcional de Caso. Butt (2006) salienta que o Caso estrutural (Nominativo e Acusativo) é independente de papéis temáticos. Esta independência é que permite a flexibilidade necessária para que o Caso estrutural se ajuste a vários tipos de verbos, ou seja, a verbo transitivos, inacusativos, passivos, entre outros.

Outra possível razão gramatical pode estar conectada com o fato de o núcleo $\mathrm{T}^{\circ}$ da sentença não entrar na derivação com Caso estrutural a valorar, o que faz com que o sujeito dos verbos transitivos tenha de vir marcado com Caso inerente. Em geral, Caso inerente está diretamente associado à atribuição de papéis temáticos pelo núcleo da estrutura vP e pode corresponder ao Caso ergativo ou ao Caso dativo. Woolford (2006), por exemplo, propõe que os Casos ergativo e dativo têm forte associação com os papéis temáticos agente e experienciador que o núcleo $\mathrm{v}^{0}$ atribui, conforme mostram as configurações sintáticas a seguir.

(8) Valoração do Caso Dativo do sujeito de verbos psicológicos:

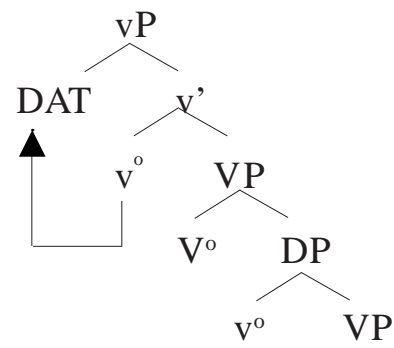


(9) Valoração do Caso ergativo do sujeito de verbos transitivos de ação:

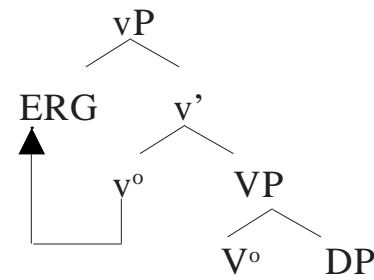

Assim, não parece ser mera coincidência que o Caso dativo marque argumentos externos com papel temático de [EXEPRIENCIADOR] e que o Caso ergativo venha correlacionado com os argumentos que apanham o papel temático de [AGENTE]. Por exemplo, no âmbito da literatura gerativa, o dativo é tratado como sendo o Caso inerente em línguas nominativas porque, em geral, está associado a argumentos que recebem papel temático de experienciador, conforme se nota pelos exemplos arrolados a seguir.

\section{Icelandic}

(10) Jóni líkuðu qessir sokkar

Jon-DAT gostar-PL essas meias-NOM

"João gosta destas meias"

(BOBALJIK, 2004, p.4)

\section{Espanhol}

(11) me encantan los niños.

me-DAT encantam os meninos-NOM

"Eu me encanto com os meninos".

Assim como dativo éo Caso inerente nas línguas nominativas, outra intuição é a de que o ergativo é o Caso inerente nas línguas ergativas. Essa correlação fica bastante visível em línguas como o Basco e o Georgiano em que verbos de ação, sejam eles transitivos ou intransitivos, marcam o seu sujeito com o Caso ergativo, e não com o Caso nominativo, conforme mostram os exemplos a seguir. 


\section{Basque}

(12) Gizona-k kurritu du

homem-ERG correr AUX

"O homem correu?"

(LEVIN, 1983, p. 33)

(13) Miren-ek atea

ireki du.

Miren-ERG porta-NOM abrir AUX

"Miren abriu a porta"

(LEVIN, 1989, p. 20)

\section{Georgian (South Caucasian: Georgia)}
(14) Vano-m
Vano-ERG
"Vano levantou o irmão"
(15) Bav $\int$ v-ma itira
Criança-ERG gritar
"A criança gritou”

gamozarda

dzma

levantar

irmão

Tal situação é o que parece também ocorrer nos exemplos da língua Warlpiri, retirados de Legate (2006), conforme abaixo.

$$
\begin{aligned}
& \text { (16) ... [ngaju-ku jarda-nguna-nja-rlarni] } \\
& \text {... I-dativo dormir-deitar-INFIN-obvc } \\
& \text { ‘... enquanto eu estava dormindo' (LEGATE, 2006, p. 19) } \\
& \text { (17) ... [karnta-patu-rlu miyi purra-nja-puru] } \\
& \text {... [mulher-pauc-ERG comida(ACC) cozinhar-INFIN-tempc] } \\
& \text { '... enquanto as mulheres estavam cozinhando'. }
\end{aligned}
$$

(LEGATE, 2006, p. 20)

Note que, em (16) e em (17), os sujeitos do verbo intransitivo e do verbo transitivo não recebem o Caso nominativo, mas sim o Caso dativo e ergativo, respectivamente. A hipótese aventada por Legate (2006) é a de que os dois Casos são valorados inerentemente no ponto da derivação sintática em que os DPs sujeitos são juntados na posição de especificador de vP. 
Outro diagnóstico, muito relatado pela literatura, para identificarmos quando os Casos ergativo e dativo são inerentes, advém do fato de que os DPs que vêm marcados com esses Casos não desencadeiam concordância com o verbo nas sentenças finitas. Isso parece ficar particularmente instanciado nas línguas Jê, uma vez que o DP com o Caso ergativo não precisa acionar morfemas de pessoa no verbo. Tal situação fica evidente pelos exemplos do Maxacali abaixo. Note que o verbo transitivo não toma prefixos de concordância de pessoa para fazer referência ao sujeito ergativo da sentença.

$$
\begin{array}{ll}
\text { (18) kakxop te kuxxamuk } & \text { paha } \\
\text { menino ERG lambari } & \text { pegar } \\
\text { "O menino pegou o lambari” } & \\
\text { (19) kakxop te tatxok } & \\
\text { menino ERG banhar } & \\
\text { "O menino (se) banha” } & \text { (CAM }
\end{array}
$$$$
\text { menino ERG lambari pegar }
$$

Outro diagnóstico refere-se à preservação do Caso inerente nas construções passivas do islandês e do alemão. Conforme salienta Woolford (2006), nessas construções, como o Caso do objeto é valorado inerentemente, ele permanece inalterado quando ocorre a transformação da voz ativa para a voz passiva, conforme mostram os exemplos a seguir:

\section{Islandês}

voz ativa

$$
\begin{aligned}
& \text { (20a) Deir skiluðu Maríu bókinni } \\
& \text { Eles devolver } \text { Mary-DAT o livro-DAT } \\
& \text { 'Eles devolveram o livro para Mary'. (JÓNSSON, 1996, p.137) } \\
& \text { voz passiva } \\
& \text { (20b) Maríu var skilað bessari bók } \\
& \text { Mary-DAT foi devolvido este livro-DAT } \\
& \text { 'Este livro foi devolvido para Mary’ (JÓNSSON, 1996, p.139) }
\end{aligned}
$$




\section{Alemão}

voz ativa

(21a) Sie hilft ihm

$$
\text { Ela o ajuda -DAT } \quad \text { (HAIDER, 1985, p. 68) }
$$

voz passiva

(21b) $\mathrm{Ihm}$

$$
\text { wird geholfen }
$$

Ele-DAT é ajudado (HAIDER, 1985, p. 68)

Observe que, nas sentenças (20a-b) e (21a-b) acima, o Caso dativo do argumento interno se mantém inalterado. Isso ocorre tanto na voz ativa quanto na voz passiva, o que, portanto, sinaliza que nesses contextos o dativo é o Caso inerente, uma vez que é preservado sob movimento-A.

Em suma, tomando por base a revisão teórica apresentada nesta seção, assumiremos, doravante, que Caso estrutural difere de Caso inerente por não ter conexão direta com a atribuição de papel temático e por envolver uma operação sintática AGREE entre um núcleo funcional da sentença e um DP que esteja em seu domínio de checagem. Caso inerente, por sua vez, terá íntima correlação com determinadas posições theta e cobre dois Casos: o dativo e o ergativo. Tendo em vista essas considerações iniciais, passemos agora à análise dos dados das línguas Jê, com o propósito de responder às três perguntas esboçadas no início deste artigo. Comecemos, então, com a discussão sobre se há, ou não, relação biunívoca entre papel theta e a valoração dos Casos dativos e ergativos.

\section{As evidências do Maxacali}

Na língua Maxacali, o Caso ergativo vem sintaticamente realizado pela posposição [te]. A ocorrência dessa adposição, enclítica a DPs, está diretamente conectada com o argumento externo que é selecionado pelos verbos transitivos de ação. Todavia, essa mesma posposição pode ainda vir enclítica a argumentos externos de certos verbos psicológicos como sentir alegria, gostar, desejar, assustar-se, ter medo, entre outros. Assim sendo, assumiremos, doravante, que a ocorrência da posposição [te] na posição enclítica a DPs, que são argumentos externos de verbos transitivos e também de verbos inergativos, está diretamente conectada com o fato de esses argumentos receberem os papéis temáticos de AGENTE, conforme evidenciam os dados a seguir. 
Transitivos de ação

(22) Konãg te tu kumuk ûhûn

[kunãy tæ? tư? kubuk' ũhusn']

Água ERG 3-SG-DAT (fazer) mal mulher-ABS

"A água fez mal para a mulher”.

(23) Pox te tik xũmũy nãm

[poj tæ2 trjk ${ }^{7} \quad \mathrm{t} \int \mathrm{tmĩj}$ nãrm?]

Flechas ERG homem-ABS acertar QT-PL

“As flechas acertaram os homens”. (CAMPOS, 2009, p.72-73)

Intransitivos de ação

(24) Kakxop te tatxok

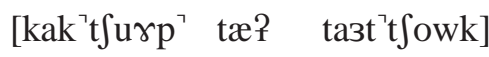

Menino ERG banhar

"O menino tomou banho".

(25) Yoãm te hãmyãg

[dzoãช્રm? tæ? hãrm’nãy]

João ERG dançar

“O João dançou”. [CAMPOS, 2009, p.72-73)

Note que os exemplos do Maxakali mostram claramente que a realização do Caso ergativo por meio da posposição [te] está diretamente correlacionada com o fato de os sujeitos de verbos transitivos de ação e de verbos inergativos receberem na estrutura argumental o papel theta [+AGENTE]. Contudo, em Maxacali, não podemos afirmar que essa relação é sempre biunívoca e sistemática, uma vez que o escopo da posposição [te] também pode estender-se a argumentos externos, doravante AEs, de verbos transitivos psicológicos, conforme mostra o exemplo a seguir:

(26) Ũn te yîmxox yîmkute

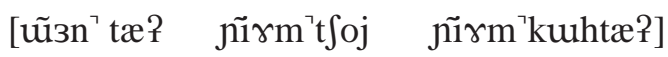

Mulher ERG marido-ABS temer

“A mulher ficou com medo do marido”. (CAMPOS, 2009, p. 79) 
O dado anterior mostra claramente que a relação entre Caso ergativo e a atribuição de papel temático [+aGENTE] não é sempre biunívoca e sistemática em Maxacali, como poderíamos, a princípio, supor, visto que, em (26), a posposição [te] figura junto ao AE que recebe papel temático [+EXPERIENCIADOR]. Uma maneira de interpretarmos teoricamente esse fato é assumirmos que, embora a função inicial da posposição [te] seja a de coocorrer com DPs com o papel theta [+AGENTE], sua ocorrência é estendida a sujeitos de verbos transitivos psicológicos. Outra possível razão pode estar conectada com o fato de a gramática do Maxacali não disponibilizar uma posposição específica de Caso dativo para marcar argumentos externos de verbos transitivos psicológicos, como ocorre, por exemplo, no Apãniekra, no Apinajé e no Parkatêjê. Nessas línguas, o sujeito dos verbos de estado psicológico coocorre com a posposição enclítica [mã]. Por esta razão, o objetivo da próxima seção é mostrar que, diferentemente do Maxacali, pode haver sim estreita biunivocidade entre a realização dos Casos ergativo e dativo, por um lado, e a atribuição dos papeis theta AGENTE e EXPERIENCIADOR, por outro, em línguas como Apinajé, Apãniekra e Parkatejê.

\section{Evidências do Apinajé, do Apãniekra e do Parkatêjê}

Em Apãniekra, Apinajé e Parkatejê, a relação entre papel theta e Caso abstrato é ainda mais forte e, de certa maneira, biunívoca. Essa biunivocidade pode ser notada pelo simples fato de o argumento externo de verbos transitivos de ação, que recebem papel theta [+AGENTE], ser marcado com a posposição de Caso ergativo [te], enquanto o argumento externo de verbos transitivos psicológicos vem marcado pela posposição de Caso dativo [mã]. Por esta razão, encontramos, nessas línguas, um padrão de Caso um pouco distinto do exibido pelo Maxacali, visto que há sim biunivocidade entre a realização dos Casos ergativo e dativo, por um lado, e atribuição dos papéis thetas [+AGENTE] e [+EXPERIENCIADOR], por outro lado. Tal relação fica assentada pelo fato de essas línguas disponibilizarem duas posposições, cujas funções morfossemânticas podem ser assim descritas, conforme Duarte (2008, 2009):

(27) a posposição [mã] coocorre com os argumentos externos de verbos psicológicos que recebem o papel theta [+EXPERIENCIADOR];

(28) a posposição [te] coaparece com argumentos externos de verbos transitivos de ação que recebem o papel theta [+AGENTE]. 
As correlações formuladas acima ficam perceptíveis quando averiguamos os contextos de distribuição das partículas [te] e [mã] nas três línguas. No Apinajé, por exemplo, a distribuição da posposição de dativo é mais ampla se comparada com a posposição de Caso ergativo, visto que ocorre tanto em orações independentes quanto em orações subordinadas nominalizadas, conforme assinalam os exemplos a seguir.

\section{Apinajé}

Orações independentes

(29) пе̃л na $\mathbf{k ə m}$ ic-kure

DEM RLS 3.DAT 1-não gostar

'Aquele ali não gosta de mim.' (OLIVEIRA, 2005, p. 236)

(30) in-mã kag̃̃ puba

1-DAT cobra RP.ter medo

'Eu tenho medo de cobras.' $\quad$ (OLIVEIRA, 2005, p.271)

Oração complexa nominalizada

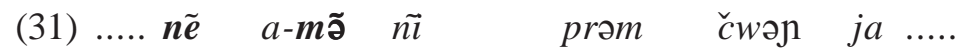

$$
\begin{aligned}
& \text { Ss 2-DAT ter sexo desejar NMLZ DET } \\
& \text { “......(aquele) com quem você quer ter sexo ......” }
\end{aligned}
$$

(OLIVEIRA, 2005, p. 259)

Diferentemente da posposição [mã], a posposição de Caso ergativo ocorre apenas em orações subordinadas nominalizadas, quando estas trazem verbos transitivos de ação, conforme apontam os dados a seguir:

Orações complexas nominalizadas

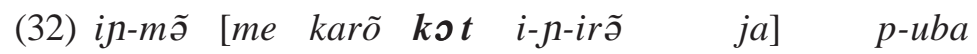
1-DAT INDF alma 3.ERG 1-RP-assistir DEF.ART RP-ter medo 'Eu tenho medo que os espíritos me assustem.'

(33) in-m̃̃ [kot [in-go j-apeə] ja] prəm 'Eu gosto dela tirando o meu piolho.' 
Situação semelhante dá-se também no Apãniekrá, visto que a posposição [mã] de dativo tem contexto de ocorrência mais amplo e tem conexão direta com os sujeitos de verbos psicológicos que recebem papel theta [+EXPERIENCIADOR], conforme sugerem os dados a seguir:

\section{Apãniekrá}

(34) j3tkahi mã a-kĩn j3tkahi-DAT tu-sentir alegria “j3tkahi gosta de você” [lit: "Você dá alegria para j3tkahi”].

(35) $i-m \tilde{a} \quad$ tep na $\quad$ prãm

eu-DAT peixe POSP querer

"Eu quero peixe”.

(ALVES, 2004, p. 117-118)

Como o Apãniekrá apresenta uma cisão de Caso condicionada pelo traço aspectual da sentença, notamos que a posposição [te] tem sua ocorrência restrita a sujeitos de verbos transitivos de ação quando a oração apresenta traço aspectual [+PERFECTIVO], conforme mostram os dados a seguir. ${ }^{3}$

$$
\begin{aligned}
& \text { (36) } i \text { - } t \varepsilon \quad a \quad j \text { - it } \varepsilon p \\
& \text { 1-ERG } 2 \text { reL cortar } \\
& \text { "eu te cortei" } \\
& \text { (37) ropti te hũmre } \varnothing \quad \text { kuran } \\
& \text { onça eRG Homem ABS matar } \\
& \text { “a onça matou o homem’ （ALVES, 2002, p.83-93) }
\end{aligned}
$$

A língua Parkatejê(FERREIRA, 2001, p. 160-167) também exibe padrão muito semelhante ao das línguas Apinajé e Apãniekra, mostrado acima, uma vez que sujeitos de verbos transitivos, os quais recebem papel theta [EXPERIENCIADOR], também vêm marcados com o Caso dativo, situação que se pode notar pela presença da posposição [mã] (= mã) nos dados a seguir. 


\title{
Parkatejê
}

(38) i-mã rop ita japê nîre eu-DAT cachorro DEM C-gostar muito “Eu gosto muito deste cachorro". (FERREIRA, 2001, p.152)

(39) i-mã tep prãm nîre

eu-DAT peixe ter.vontade muito

"Eu gosto muito de peixe”. ～(FERREIRA, 2001, p.160)

Já em orações com verbos transitivos de ação, o sujeito vem acompanhado da partícula [te], conforme se vê no exemplo abaixo.

$$
\begin{array}{lll}
\text { (40) } i \text {-te } & i \text {-kra } & \text { pan } \\
\text { eu-ERG } & \text { 1-filho } & \text { carregar+PASs }
\end{array}
$$

"Eu carreguei meu filho"

(FERREIRA, 2001, p.159)

Contudo, oposto ao que ocorre no Maxacali, em Parkatêjê, sujeitos de verbos inergativos, assim como se dá no Apãniekra e Apinajé, não tomam a posposição [te] de Caso ergativo, muito embora recebam papel temático [AGENTE], conforme mostram os exemplos a seguir.

\section{Parkatejê}
(41) mẽ mpy
tor
PL homem dançar-PAss
“Os homens dançaram”.

\section{Apãniekrá}

\author{
(42a) $h$-зрзп \\ 3-comer \\ ‘ele comeu (há pouco tempo) \\ (42b) i-mõr \\ 1-andar \\ “eu andei”
}


(43) $i$ i?- $\eta \mathrm{kr \varepsilon r}$

3-cantou

'ele cantou'

(ALVES, 2004, p. 68, 109 e 111)

O curioso nas sentenças de (41) a (43) é que, muito embora o verbo esteja na sua morfologia de tempo passado e apresente o traço aspectual [+perfectivo], a posposição [te] de Caso ergativo não é acionada. Uma explicação plausível para entendermos a razão por que o Caso ergativo não é acionado pelo sujeito do verbo nesses exemplos pode ser encontrada se assumirmos que o Caso desse argumento évalorado estruturalmente, no domínio funcional da sentença, e não internamente no domínio v-VP, como parece ocorrer com o sujeito dos verbos transitivos.

Tendo em conta a distribuição morfossintática das posposições [te] e [mã] (= mã) nas línguas Jê avaliadas até aqui, ficamos em condições de responder à primeira pergunta proposta no início deste artigo. A nossa hipótese, seguindo Duarte (2008, 2009), é a de que a realização dos Casos ergativos e dativos tem sim forte conexão com a atribuição dos papéis temáticos [AGENTE] e [EXPERIENCIADOR]. Contudo, o que a nossa análise precisa determinar é se os Casos ergativos e dativos são inerentes ou se são estruturais. Esta questão, por sua vez, remete-nos a uma outra, que tem a ver com o estatuto sintático das posposições funcionais [te] e [mã]. Explorar o escopo dessas adposições e definir a natureza dos Casos ergativo e dativo será o objeto de nossa investigação na próxima seção.

\section{Estatuto das posposições [te] e [mã] e fonte de valoração do caso ergativo e dativo nas línguas Jê}

Conforme sinalizamos acima, assumiremos que as marcas de Caso ergativo [te] e de Caso dativo [mã] nas línguas Jêt são posposições. Mais precisamente, proporemos que [te] e [mã] sejam interpretadas teoricamente como posposições de natureza funcional, cuja função é, de um modo geral, valorar o Caso de argumentos externos de verbos transitivos ativos, conforme demonstra a configuração em (44): 
(44)

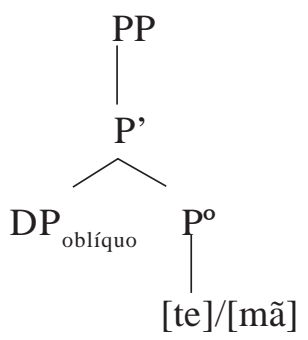

A estrutura em (44) pressupõe que as posposições [te] e [mã] encabeçam o núcleo $\mathrm{P}^{\circ}$ capaz de valorar o Caso estrutural do DP que ocupa a posição de seu complemento. Acompanhando proposta de Barcelos Silva (2009, 2010), nossa hipótese é a de que o PP encabeçado por essa posposição é juntado na posição de Spec-vP, de modo a atender as propriedades selecionais do núcleo $\mathrm{v}^{\mathrm{o}}$. A hipótese de que [te] e [mã] sejam, de fato, núcleos posposicionais fica evidenciada pela análise dos dados do Apãniekrá, do Apinajé e do Maxacalí.

Em Apãniekrá, por exemplo, a partícula [te], além de marcar Caso ergativo, figura também em construções genitivas, como núcleo de um sintagma posposicional, para sinalizar o material com que o item especificado é feito. Vejamos os exemplos a seguir:
(45) Karẽk te pririr
Argila GEN animal
'animal de argila'
(46) Ken te wakə
Pedra GEN faca
'faca de pedra'
(47) pur ita i-tõj te kje
Roça DEM 1-irmã GEN POSS
'esta roça é da minha irmã' $\quad$ (ALVES, 2004, p.87 e 155)

Além disso, verificamos que em Apãniekrá, assim como também se dá com as demais posposições da língua, tanto [te] quanto [mã] podem coocorrer com as formas pronominais clíticas. Segundo Alves (2004), os pronomes prefixais aparecem em Apãniekrá junto a um núcleo lexical seja ele um nome, um verbo 
ou uma posposição. Assim sendo, os pronomes prefixais figuram como possessivos ou sujeitos de predicado nominal, como sujeitos de verbos (intransitivos) no passado simples ou objeto de verbos transitivos e como objetos de posposições. A seguir, arrolamos o quadro com o inventário dos pronomes clíticos na língua: ${ }^{5}$

\begin{tabular}{|l|l|}
\hline 1 inclusivo dual & pa (?)- \\
1 inclusivo plural & $\mathrm{m} \tilde{\varepsilon}=\mathrm{pa} \mathrm{(?)}$ \\
1 singular & $\mathrm{i}-$ \\
1 exclusivo plural & $\mathrm{m} \tilde{\varepsilon}=\mathrm{i}-$ \\
2 singular & a- \\
2 plural & $\mathrm{m} \tilde{\varepsilon}=\mathrm{a}-$ \\
3 singular & $\mathrm{i}(\mathrm{P})-/ \mathrm{h}-/ \mathrm{ku}-/ \varnothing$ \\
3 plural & $\mathrm{m} \tilde{\varepsilon}=\mathrm{i}(\mathrm{P})-\mathrm{m} \tilde{\varepsilon}=\mathrm{h}-/$ \\
& $\mathrm{m} \tilde{\varepsilon}=\mathrm{ku}-/ \mathrm{m} \tilde{\varepsilon}=\varnothing$ \\
\hline
\end{tabular}

Nas orações abaixo, podemos observar os prefixos acima coocorrendo com as posposições [te] e [mã]:
(49) $i$-te amji $t \varepsilon \quad k \tilde{w i n}$
1-ERG RFL Perna quebrar
'eu quebrei a perna'

(50) $m \tilde{\varepsilon}=$ pa?-te ajpen pupun

$\mathrm{PL}=$ 1-INCL-ERG RCP ver

'nós nos vimos (eu vi você e você me viu)'

(51) a-te ken kapon

2-ERG pedra partir

'você partiu a pedra'

(52) $k u-t \varepsilon \quad k r u w \quad k \tilde{w i n}$

3-ERG flecha quebrar

'ele quebrou a flecha' 


$$
\begin{aligned}
& \text { (53) i-mã } \quad h \text {-ũpa } \\
& \text { 1-DAT 3-sentir medo } \\
& \text { 'eu senti medo dele' } \\
& \text { (54) } a-m \tilde{a} \quad \text { prãm } \\
& \text { 2-DAT sentir.fome } \\
& \text { 'você está com fome' } \\
& \text { (55) ku-mã kĩn } \\
& \text { 3-DAT sentir.alegria } \\
& \text { 'ele está alegre' }
\end{aligned}
$$

(ALVES, 2004, p. 60,70, 71 e 113)

Em Apinajé verificamos situação semelhante. Nesta língua, as marcas do Caso ergativo são as partículas [te] e [kot]. Segundo Oliveira (2005), tais morfemas podem figurar em oração ergativa, a qual aparece, exclusivamente, em contextos de subordinação. De acordo com a autora, [te] acompanha sujeitos agentes e recebe marca de pessoa. [kot], por sua vez, é usado apenas na terceira pessoa e não recebe flexões pessoais. Uma forte evidência a favor da hipótese de que $\mathbf{t} \boldsymbol{\varepsilon}$ e kot representem núcleos posposicionais é a ocorrência de prefixos pessoais junto a essas posposições em Apinajé. Segundo Oliveira (2005), nessa língua as categorias de pessoa são expressas por praticamente o mesmo conjunto de prefixos em três categorias lexicais, a saber: verbos, nomes e posposições. Em vista disso, a autora elabora a seguinte tabela elencando os prefixos pessoais que sempre acompanham as posposições:

\section{(56) Prefixos de Pessoa}

\begin{tabular}{|l|l|}
\hline $\mathrm{i}(\mathrm{c})-$ & ' 1 ' \\
$\mathrm{a}-$ & '2' \\
$\varnothing-$ & '3' \\
(ku- & '3') \\
\hline
\end{tabular}

Os dados do Apinajé mostram que a marca ergativa [te] pode coocorrer com os mesmos prefixos de $1^{\mathrm{a}}$ e $2^{\mathrm{a}}$ pessoas que acompanham as demais posposições. Ademais, Oliveira (2005), em análise da marca ergativa [kot], afirma que o prefixo ku-de terceira pessoa pode ter participado do desenvolvimento dessa forma supletiva do ergativo. Segundo a autora, a forma originária de kot seria ku-tॄ; e com a frequência do uso, as vogais envolvidas na forma ku-tॄ 
teriam passado por mudanças fonológicas dando origem à forma monossilábica - [kot]. Oliveira (2005) estende o mesmo raciocínio para duas outras posposições do Apinajé que também acionam formas supletivas de terceira pessoa - [kəm] e [kəp], conforme mostram os dados a seguir:

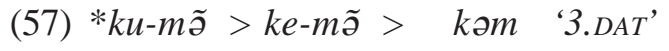

$$
\begin{aligned}
& \text { *ku-pe > ke-pe > kep '3.DTR' } \\
& \text { *ku-t } \varepsilon>\text { ko-t } \varepsilon>\text { kot '3.ERG' }
\end{aligned}
$$

Ora, se [te] pode vir com os prefixos pessoais próprios das posposições e se, em Apinajé, apenas as categorias lexicais nomes, verbos e posposições podem ser codificadas por prefixos pessoais, há que se concluir que [te] e, consequentemente, a forma supletiva de terceira pessoa [kot] possuem 'status' de posposições nessa língua. Nos exemplos abaixo, podemos observar os prefixos pessoais e a marca $\boldsymbol{k} \boldsymbol{t}$ em construções ergativas.

$$
\begin{aligned}
& \text { (58) a. ic-te a-bar ket } \\
& \text { 1-ERG 2-entender NEG } \\
& \text { 'Eu não te entendo' } \\
& \text { b. ic-te a-punbuji } \\
& \text { 1-ERg 2-verNF }
\end{aligned}
$$

'Eu te entendo'

(OLIVEIRA, 2005, p.237)

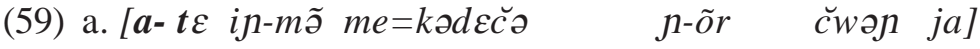
2-ERG 1-DAT INDF=contrapartida RP dar NF NMLZ DEF.ART na ra $\varnothing \quad$ omduju
RLS ASP 3 3.mal

'Este medicamento que você me deu já está vencido’

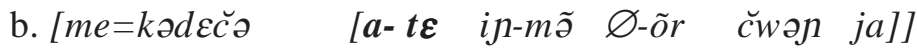

$$
\begin{aligned}
& \text { INDF=contrapartida 2-ERG 1-DAT 3darNF NMLZ DEF.ART } \\
& \text { na } \quad \text { ra } \varnothing \quad \text { omduju } \\
& \text { RLS ASP } 3 \text { 3.mal }
\end{aligned}
$$

'Este medicamento que você me deu já está vencido'

(OLIVEIRA, 2005, p.284) 
(60) in-mã [me karõ kot i-n-ir̃̃ ja] p-uba 1-DAT INDF alma 3.ERG 1-RP-assistir DEF.ART RP-ter medo

'Eu tenho medo que os espíritos me assustem.'

(OLIVEIRA, 2005, p.278)

(61) b. iø-m̃ [kot [in-go j-apeə] ja] prəm 1-DAT 3.ERG 1-piolho RP-procurar DEF.ART gostar 'Eu gosto dela tirando o meu piolho.'

(OLIVEIRA, 2005, p.280)

Outra forte evidência a favor da hipótese de que a marca de Caso ergativo é uma posposição em línguas Jê são as construções passivas em Maxacali. Analisemos os seguintes exemplos:

Voz ativa

\begin{tabular}{|c|c|c|c|}
\hline 62a) Kakxop & $-t e$ & okoat & kõyõy \\
\hline 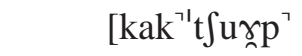 & tæ? & Poku'aş $\mathrm{t}^{\urcorner}$ & n] \\
\hline Menino & ERG & соро & rar \\
\hline
\end{tabular}

'O menino quebrou o copo'

Voz passiva

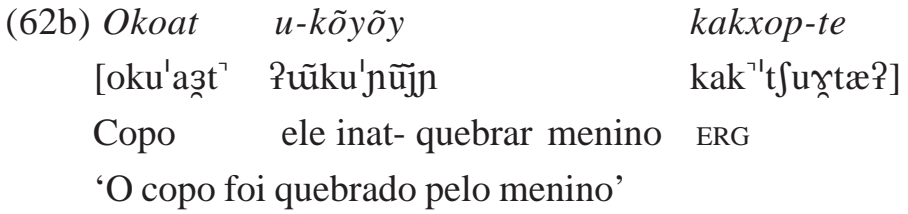

Voz ativa

(63a) А̃mu'u -te тїтхих рор-то̃g

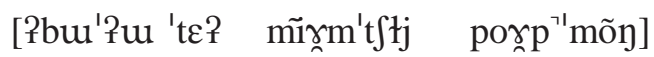

Vento ERG árvore folha pegar ir PL

'O vento levou as folhas' 
Voz passiva

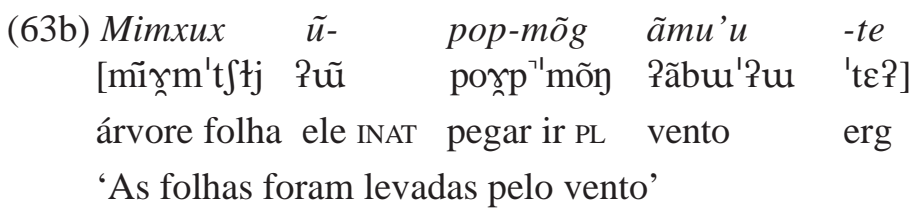

(CAMPOS, 2009, p. 245 e 246)

A ocorrência de uma adposição junto a DPs agente em construções passivas é recorrente nas línguas, o que leva a crer que em (62b) e em (63b), [te] se comportaria como uma posposição. Além disso, pesa a favor de nossa hipótese o fato de [te] poder ser substituído pela posposição [tu] nas sentenças passivas. Nas construções passivas em Maxacali, [tu] é uma posposição que significa 'por'. Ora, se [tu] pode ser substituída por [te] sem qualquer alteração no significado da sentença, podemos inferir que [te] também corresponde a uma posposição em Maxacali. Vejamos os exemplos a seguir:

Voz ativa

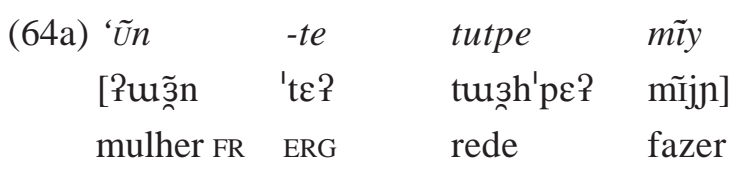

'A mulher fez uma rede'

Voz passiva com te

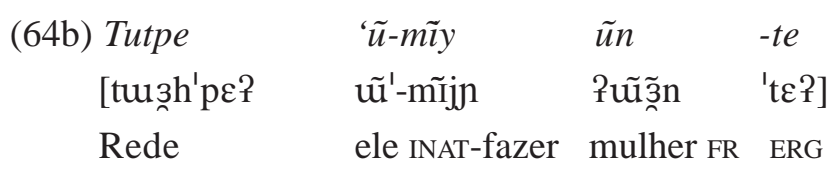

'A rede foi feita pela mulher'

Voz passiva com tu

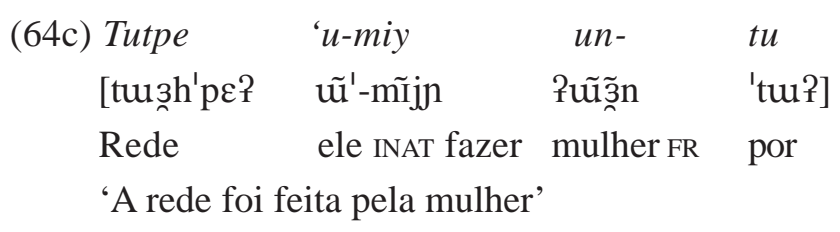


Voz ativa

\begin{tabular}{|c|c|c|c|}
\hline (65a) Tappet-mĩy-ax & -te & tappet & kax-ãmix \\
\hline 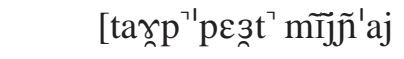 & & 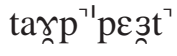 & kajã'brj] \\
\hline Papel fazer -NOML & ERG & papel & som rabiscar \\
\hline
\end{tabular}

Voz passiva com te

\begin{tabular}{|c|c|c|c|}
\hline (65b) Tappet & 'ũ-kax-ãmix & tappet-mĩy-ax & -te \\
\hline$\left[\operatorname{tar} \mathrm{p}^{\urcorner 1} \mathrm{p} \varepsilon \mathrm{s}^{\mathrm{n}}{ }^{7}\right.$ & جũ̃kajã'brj & 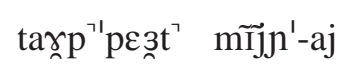 & 't $\varepsilon ?]$ \\
\hline Papel & ele INAT-rabis & rpapel fazer-NOML & ER \\
\hline
\end{tabular}

Voz passiva com tu

\begin{tabular}{|c|c|c|c|}
\hline (65c) Tappet & 'ũ-kax-ãmix & tappet-mĩy-ax & $-t u$ \\
\hline [tarp $\mathrm{p}^{\urcorner 1} \mathrm{p} \varepsilon 3 \mathrm{n}^{\urcorner}$ & جũkkajã'brj & 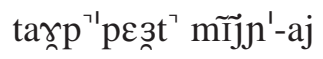 & 'tur?] \\
\hline Papel & ele INAT-rabiscar & papel fazer-NOML & ERG \\
\hline
\end{tabular}

(CAMPOS, 2009, p. 246)

Nas sentenças acima, vemos que [te] é intercambiável com a posposição [tu] sem que haja mudança no sentido da sentença. Em sendo assim, os dados do Maxacali vêm corroborar a análise de que a marca de Caso ergativo [te] é, de fato, uma posposição.

É preciso ressaltar que um dos diagnósticos utilizados pelos que consideram o Caso ergativo como Caso inerente é sua ocorrência em construções onde $\mathrm{T}^{\circ}$ é inerte/não finito, principalmente em orações encaixadas/nominalizadas. ${ }^{6}$ Segundo essa análise, Caso nominativo está diretamente relacionado à finitude da sentença. Conforme mostrado na seção 2 , nas construções finitas, o núcleo $\mathrm{T}^{\circ}$ atua como uma sonda ${ }^{7}$ buscando um DP (alvo) dentro de seu domínio de checagem, de modo a poder valorar o Caso nominativo numa relação de ccomando. Em vista disso, assumem alguns teóricos que, nos contextos de sentenças transitivas, onde o núcleo $\mathrm{T}^{0}$ é defectivo [-finito] e não entra na derivação com Caso a valorar, as línguas optam pelo Caso inerente a ser licenciado para o argumento externo. 
Contudo, o que verificamos, nas línguas do tronco linguístico Macro-Jê, é que, sendo $\mathrm{T}^{\circ}$ não finito, e, consequentemente, inapto a valorar Caso nominativo, o núcleo $\mathrm{P}^{\mathrm{o}}$, realizado pela posposição [te], deve ser inserido, como operação de último recurso, ${ }^{8}$ para valorar o Caso dos sujeitos de sentenças transitivas no passado recente, como é a situação no Apaniekrá e no Parkatejê. A inserção de uma adposição (i.e., uma preposição ou uma posposição), como uma operação de último recurso para permitir valoração de Caso abstrato não é um fenômeno raro nas línguas, podendo ser observado inclusive no português brasileiro. A título de exemplificação, tomemos como exemplos as seguintes construções do PB chamadas de causativas não analíticas e que se caracterizam por denotar duplacausação:

(66) Luma fez sua fantasia com costureiras da escola de samba

(67) João consertou seu carro com mecânico

Nos exemplos acima, vemos que ambas as orações apresentam dois argumentos com as propriedades semânticas de \{desecandeador/controle\}: o DP "Luma” e o DP “costureiras da escola de samba”, no exemplo (66), e o DP “João” e o DP “mecânico”, no exemplo (67). Os dados sugerem que, nessas estruturas, embora haja três argumentos para receber Caso estrutural, existem apenas dois núcleos disponíveis a valorar Caso abstrato, a saber: o núcleo $\mathrm{T}^{ } \mathrm{e}$ o núcleo $\mathrm{V}^{0}$. Nesse sentido, nossa proposta é a de que, na sentença (66), o argumento "Luma” e, na sentença (67), o argumento “João”, que carregam as propriedades semânticas \{desencadeador/controle, não afetado\}, recebem Caso nominativo do núcleo $\mathrm{T}^{\circ}$ e os argumentos internos recebem Caso acusativo do núcleo v ${ }^{0}$. Como não há mais núcleos funcionais disponíveis para valorar o Caso abstrato do terceiro argumento, representado pelos DPs "costureiras da escola de samba” em (66) e "mecânico" em (67), uma operação de último recurso deve ser acionada para evitar que esse DP fira o filtro de Caso e fique sem receber Caso. A sintaxe do PB soluciona esse problema por meio da inserção da preposição “com” para valorar o Caso oblíquo ao terceiro argumento das sentenças em (66) e (67).

Em análise dos dados das línguas Jê, verificamos exatamente o mesmo fenômeno: a posposição [te] é inserida para valorar apenas o Caso de sujeitos de verbos transitivos, particularmente os que denotam ação, mas não contribui com a atribuição do papel temático. Note que o DP argumento externo, 
selecionado pelo núcleo $\mathrm{V}^{0}$, é um argumento acarretado semanticamente pelo verbo leve e não pela posposição.

A inserção da posposição como recurso para atribuir Caso aos sujeitos de transitivos, quando o núcleo $\mathrm{T}^{\circ}$ não se encontra ativado, pode ser observada nas línguas Apãniekrá, Xavante e Apinajé. No sistema ergativo/absolutivo do Apãniekrá, por exemplo, a ausência de partículas de tempo evidencia que o núcleo $\mathrm{T}^{0}$ não entra na derivação com Caso abstrato a valorar. Além disso, verificamos que a morfologia verbal pode vir na sua forma finita, conforme mostram os exemplos em (a), ou na forma não finita, conforme exemplos em (b). Note ainda que, nos pares de sentenças abaixo, a modificação na forma do verbo fica evidente quando as orações se encontram no tempo passado simples:

Forma finita

(68a) wa ha $t \int$-war

1 iRR PR-banhar

'eu vou (me) banhar'

Forma não finita

(68b) $i-t \int-w \partial r$

1-pr-banhar

'eu (me) banhei’ (passado simples)

Forma finita

(69a) wa ha ap3

1 irr comer

'eu vou comer'

Forma não finita

(69b) $h$-зр зи

3-comer

‘ele comeu’ (passado simples) 
Forma finita
(70a) pe rop
i-t $\int a$
PD cachorro 1-morder
'o cachorro me mordeu'
(quando eu era pequena - passado distante)

Forma não finita
(70b) rop te i-t tar
Cachorro ERG 1-morder
'o cachorro me mordeu
(há pouco tempo - passado simples)

(ALVES, 2004, p. 65 a 68)

Conforme evidencia o exemplo (70b), sendo o núcleo $\mathrm{T}^{\mathrm{0}}$ não finito e, portanto, inapto a valorar Caso nominativo, o núcleo $\mathrm{P}^{\mathrm{o}}$, realizado pela posposição $\mathbf{t} \boldsymbol{\varepsilon}$ [te], é inserido em orações transitivas no passado simples, como resultado de uma operação de último recurso para valorar o Caso dos sujeitos.

Em Xavante e Apinajé, o Caso nominativo não é licenciado para sujeitos de verbos transitivos em orações subordinadas nominalizadas, porque 'tempo' não vem realizado por nenhuma partícula que costuma ocorrer no domínio C/TP. Os dados, a seguir, comprovam esse fato.

\section{Xavante}

(71) $2 w$ 1 ERG 3-fazer-NZR te $\Upsilon \check{\imath}-b a \tilde{d} d z \tilde{a}-r \grave{l} ?$ tsi१õdõ hã

cesto ENF "Foi feito por nós dois, o cesto".

(McLEOD E MITCHELL , 1977, p. 160)

\section{Apinajé}

(72) in-mə [relat kot in-go j-apeə ja] prom 1-DAT 3.ERG 1-piolho RP-procurar DEF.ART GOSTAR 'Eu gosto dela tirando o meu piolho.' 


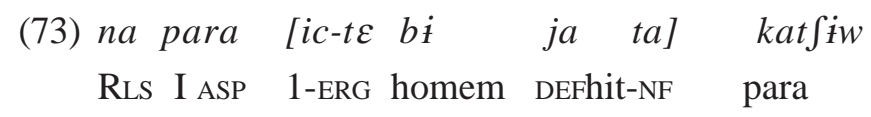

"Eu estou quase batendo neste cara".

(OLIVEIRA, (2002, p. 280-290)

Os dados do Xavante e do Apinajé são bastante interessantes, porque mostram que o surgimento do Caso ergativo está diretamente conectado com o fato de as orações complemento serem um tipo de "big DP” em que o núcleo $\mathrm{T}^{0}$ não está apto a valorar o Caso nominativo. Esses exemplos corroboram a análise até aqui desenvolvida e exibem o acionamento da posposição [te] quando o núcleo $\mathrm{T}^{\circ}$ é defectivo.

Tomando por base os dados das línguas Jê examinadas até aqui, proporemos, de acordo com Barcelos Silva (2009; 2010), que o Caso ergativo não será inerentemente atribuído conforme prediz Woolford (1997, 2006), mas, ao contrário, corresponde a Caso estruturalmente valorado pela posposição [te]. Dessa maneira, o que a literatura sobre ergatividade em línguas Jê denomina Caso ergativo corresponde, ao final das contas, a Caso oblíquo, que é valorado por uma posposição funcional. Dessa maneira, em contextos de sentenças transitivas no passado recente, como se dá no Apãniekrá e Parkatejê, e em orações subordinadas não finitas, como no Xavante e Apinajé, assumiremos que o núcleo $\mathrm{T}^{0}$ não entra na derivação com traço de Caso estrutural a valorar, sendo, portanto, inapto a buscar um DP alvo para valorar Caso nominativo.

Em suma, tomando por base os dados das línguas Jê, postularemos, em conformidade com Barcelos Silva (2009; 2010) que, nessas línguas, um núcleo posposicional será introduzido na derivação como operação de último recurso para permitir a valoração do Caso dos argumentos externos dos verbos de ação. Isso significa que o DP agente, possível candidato a receber o Caso nominativo, receberá, na verdade, Caso estrutural da posposição [te]. Este Caso equivale ao oblíquo, conforme mostra a configuração sintática a seguir: 


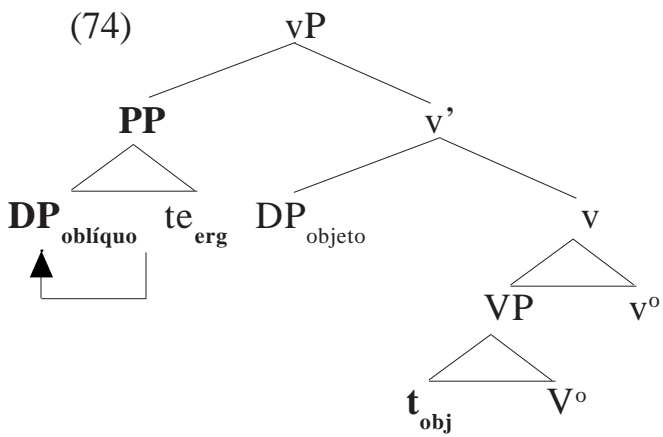

Em vista do que foi postulado, assumiremos que Caso ergativo em línguas Jê não será exatamente Caso inerente nos termos propostos por Woolford (1997, 2006). Ao contrário, corresponderá a Caso oblíquo, o qual é valorado estruturalmente numa relação de irmandade e de localidade entre a posposição [te] e o DP que ocupa a posição de sujeito da sentença transitiva.

Como corolário do que acabamos de propor, se considerarmos que a partícula [mã], que acompanha os sujeitos com o papel temático EXPERENCIADOR, também se trata de uma posposição, o Caso dativo dos sujeitos experenciadores corresponderá a Caso oblíquo, e não Caso inerente. Destarte, assim como se dá com os objetos indiretos, o Caso dativo dos sujeitos experenciadores corresponde à Caso oblíquo, conforme sinalizam os exemplos a seguir:

\section{Apãniekrá}

Caso dativo em objetos indiretos (contexto de verbo transitivo trivalente)
(75) $i$ - $t \varepsilon$ ramã Pedromã
$m 3 k$ $n$ - $\tilde{\jmath} r$
1 -ERG
ASP PEDRo Dat
mocó PR-dar
‘eu dei mocó para o Pedro’
(76) $i-t \varepsilon$

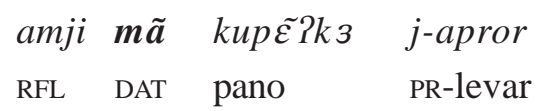
1 -ERG
RFL DAT pano
(77) $k u-t \varepsilon$ amji prõ $\boldsymbol{m} \tilde{\boldsymbol{a}}$

$$
\text { kup } \tilde{\varepsilon} ? k 3 \quad t o=t \tilde{\varepsilon} m
$$$$
\text { 3-eRg RFL esposa DAT pano CAUS=ir }
$$$$
\text { 'ele levou pano para sua esposa' }
$$

(ALVES, 2004, p. 62,70) 
Caso dativo de sujeitos experenciadores

(78) $i$-m̃ $\quad h$ - ũpa

1- DAT 3-sentir medo

'eu estou com medo dele'

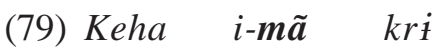

fut 1-DAT ter frio

"eu vou ficar com frio"

(80) $i-m \tilde{a} \quad k r \dot{t}$

1-DAT ter frio

"eu estou com frio"

(81) j3tkahi mãa $\quad a-k$ in j3tkahi- DAT tu-sentir alegria

‘j3tkahi gosta de você” [lit: você dá alegria para j3tkahi]

(ALVES, 2004, p. 56, 113 e 117)

\section{Apinajé}

Caso dativo em objeto indireto

$\begin{array}{cllll}\text { (82) na [ireptsi } & \text { ne } & \text { kačíw } & \text { tijj } & \text { dada] } \\ \text { RLS N. } & \text { CNJ além disso } & \text { HT } & \text { N. }\end{array}$

na [wa] in-mã kwərčən go

RLS DU 1-DAT macaxeira dar

'Ireptsi, junto com Dada, âmbar me deram macaxeira

(OLIVEIRA, 2005, p. 212)

Caso dativo de sujeitos experenciadores
(83) пе̃л па $\mathbf{k ə m}$
ic-kure
DEM RLS 3-DAT
1-não gostar

'Aquela ali não gosta de mim' 
(84) in-m̃ [[akunĩ kot ic-tem] ja] pu-ba 1-DAT floresta DIR 1-ir.NF DEF RP-ter medo

'Eu tenho medo de caminhar na floresta'

(OLIVEIRA, 2005, p. 236)

Ao assumirmos que, nas línguas Jê, os Casos ergativo e dativo equivalem a Caso estrutural e não a Caso inerente, ficamos em condições de responder satisfatoriamente à questão (2) proposta no início deste trabalho, ou seja, o dativo e o ergativo equivalem a Caso oblíquo valorado pelas posposições [te] e [mã].

Resta-nos, porém, analisar como fica a atribuição de papel temático aos argumentos externos que exibem o Caso ergativo e o Caso dativo, tendo em vista a forte correlação entre eles e os papéis, respectivamente, de [AGENTE] e [EXPERENCIADOR]. A próxima seção busca detalhar nossa proposta a esse respeito.

\section{Por que há forte conexão entre papel theta e Caso?}

A questão que se coloca é saber exatamente se as posposições [te] e [mã] contribuem ou não na atribuição do papel temático dos DPs com os quais coocorrem. Para tanto, analisemos a seguinte oração do Apãniekrá:

$$
\begin{array}{ccccc}
\text { (85) } k u k^{h} \varepsilon n \quad t \varepsilon & \text { ampotfo } & \varnothing & k^{h} r \varepsilon r \\
\text { Cotia ERG fruta } & \text { ABS } & \text { comer } \\
\text { "a cotia comeu a fruta” } & &
\end{array}
$$

Observe que a posição de sujeito nesta oração é ocupada pelo PP "kuk $\boldsymbol{\varepsilon} \mathbf{t} \boldsymbol{t}$ ”. Note ainda que, apesar de esse sintagma ser o complemento da posposição t $\varepsilon$, o papel temático não será por ela atribuído. Em análise à sentença, verificamos que o DP "kuk $\mathbf{k}^{\mathbf{k}} \boldsymbol{\varepsilon}$ ” é o agente da ação denotada pelo verbo comer "khrer". Assim sendo, esse DP apresenta as propriedades semânticas de \{desencadeador/controle/não afetado\}. Assumiremos que o DP "kukk $\boldsymbol{\varepsilon}^{\mathbf{h}}$ " é, por conseguinte, um argumento acarretado semanticamente pelo verbo " $\mathbf{k}^{\mathbf{h}} \mathbf{r \varepsilon r}$ " "comer”, fazendo parte de sua estrutura argumental, e não da estrutura argumental da posposição t $\boldsymbol{\varepsilon}$, visto ser esta posposição um núcleo de caráter funcional, desencadeada nesses contextos para valorar o Caso do argumento externo. 
Acompanhado proposta de Cançado (2009), admitiremos que "os argumentos de um predicador, no caso mais específico, de um verbo, são todas as informações de sentido, ou propriedades semânticas, acarretadas lexicalmente por esse verbo para que seu sentido se sature”. Verificamos que, em termos de estrutura argumental, as orações transitivas de ação acarretam lexicalmente um argumento agente, ou melhor, um argumento desencadeador com controle, que realiza a ação denotada pelo verbo. No caso do Apãniekra, vimos que esse argumento será sempre seguido pela posposição te.

Em vista disso, apesar de o argumento desencadeador com controle se situar na posição de complemento da posposição t $\boldsymbol{\varepsilon}$, núcleo do PP selecionado pela estrutura vP, tal argumento, na verdade, não é acarretado semanticamente pela posposição, mas sim pelo verbo.

Cançado (2009), analisando argumentos preposicionados em posição de adjunção, mas que são acarretados semanticamente pelo verbo no $\mathrm{PB}$, postula que "se (...) o complemento da preposição for um argumento do verbo, a preposição que encabeça esse argumento só tem a função sintática de atribuir caso, ou seja, é uma preposição funcional”. A autora ilustra sua hipótese considerando os argumentos do verbo vender, conforme exemplo a seguir:

(86) Os rapazes vendem um carro para Maria por cem mil reais.

Segundo Cançado (2009), os papéis temáticos de “Maria” como um alvo e de "cem mil reais" como valor do objeto envolvido no processo fazem parte da estrutura argumental do verbo vender. Assim, as preposições que encabeçam esse argumento seriam funcionais, não atribuidoras, pois, de papel temático, sendo inseridas na estrutura sintática apenas para permitir a valoração de Caso desses argumentos, já que não há outro núcleo disponível para valorar seu Caso.

Tomando por base essas considerações teóricas, ficamos em condições de decidir como se dáa atribuição de papel temático ao DP complemento da posposição [te]. Nessa linha de raciocínio, conforme Barcelos Silva (2009; 2010), assumiremos que o argumento que apresenta as propriedades de \{desencadeador /controle\} é acarretado semanticamente pelo verbo, e não pela posposição. Concluímos que tal posposição é, na verdade, apenas de natureza funcional, uma vez que não confere qualquer função semântica a seu complemento. A posposição [te], segundo esse ponto de vista, deve ser entendida apenas como núcleo de um PP, cujo complemento é argumento de outro predicador. Sua função é, tão somente, a de atribuir Caso a esse argumento, e não papel temático. Em vista disso, 
concluímos que o papel temático de agente \{desencadeador/controle\} desempenhado pelo DP complementos da posposição [te], é atribuído pelo núcleo de vP e não pela posposição cuja função única é atribuir Caso. $O$ fato interessante que difere as línguas ergativas do português é que, naquelas, a adposição figura enclítica a argumentos externos acarretados pelo verbo, enquanto, no PB, a adposição figura proclítica a argumentos em posição de adjunção. Outra característica curiosa da posposição [te] -é que, além de licenciar o Caso oblíquo, também exibe uma conexão direta com o papel temático de desencadeador com controle. Essa relação é tão interessante, que, por exemplo, no Apãniekrá, a posposição [te] - não aparecerá nas orações em que o sujeito não é agente, mesmo quando essas orações estiverem no passado, conforme os exemplos a seguir, em que o sujeito tem a propriedade semântica de ser afetado:

$$
\begin{array}{lll}
\text { (87) } \begin{array}{l}
i-n-i= \\
1-\text {-PR-carne }=
\end{array} & k \text { engordar } & \\
\text { 'eu engordei' } & \\
\text { (88) } i-n-i= & \text { kutor } & \\
1 \text {-PR-carne }= & \text { emagrecer } & \\
\text { 'eu emagreci' } & & \text { (ALVES, 2004, p. 99 e 100) }
\end{array}
$$

Além disso, se o sujeito recebe do verbo o papel temático de experenciador, o argumento externo será seguido da posposição [mã], conforme mostramos nas seções 2 e 5. Tal posposição em Apãniekrá tem contexto de ocorrência mais amplo, pois tem conexão direta com os sujeitos que recebem papel temático de [EXPERIENCIADOR], tanto em orações que apresentam o traço aspectual perfectivo quanto em orações que carreguem traço aspectual imperfectivo, conforme mostram os dados repetidos a seguir:

$$
\begin{aligned}
& \text { (89) } \begin{array}{l}
\text { i-mã } \\
\text { 1- DAT }
\end{array} \text { 3-sentir medo } \\
& \text { 'eu estou com medo dele’ } \\
& \text { (90) Keha i-mã } \quad k r \dot{a} \\
& \text { FUT } \quad \text { 1-DAT } \quad \text { ter frio } \\
& \text { "eu vou ficar com frio" }
\end{aligned}
$$




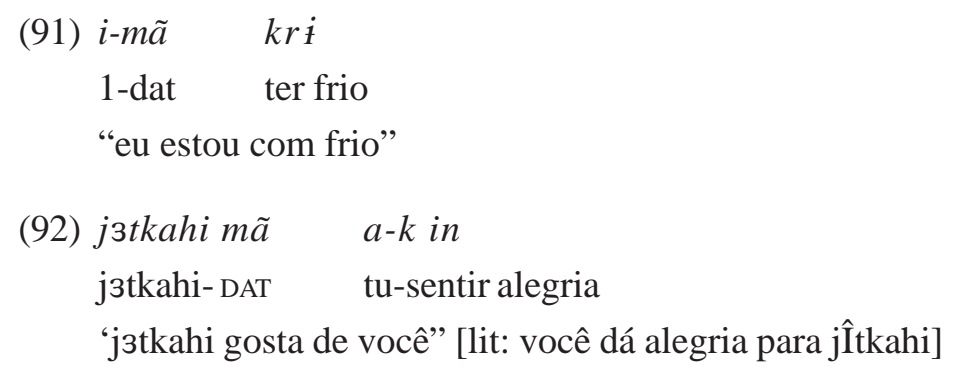

(ALVES, 2004, p. 56, 113 e 117)

Em síntese, esses fatos dão sustentação adicional à nossa hipótese de que (i) as posposições [mã] e [te] não participam da atribuição de papel temático dos sujeitos das orações e (ii) os argumentos fazem parte da estrutura argumental dos verbos, embora tenham seu Caso abstrato valorado por essas posposições. Desse modo, [mã], assim como [te], também se comporta como uma posposição funcional, cuja função é permitir a valoração do Caso abstrato do argumento externo de verbos transitivos psicológicos.

\section{Considerações Finais}

Com base na proposta desenvolvida até aqui, concluímos que as posposições [mã] e [te] têm a função de valorar Caso oblíquo dos argumentos externos de verbos transitivos no conjunto das línguas Jê examinadas neste artigo. Sendo assim, em vista dos dados, da argumentação e da análise delineada até aqui, proporemos que [mã] é apenas uma posposição de natureza funcional que valora o Caso oblíquo (=dativo) dos sujeitos de verbos psicológicos e de certos intransitivos estativos. Esses sujeitos recebem, por sua vez, o papel temático de experenciador do verbo que os s-seleciona. Por sua vez, admitiremos que [te] é uma posposição funcional que valora Caso oblíquo (=ergativo) dos sujeitos de verbos transitivos e intransitivos de ação. Esses sujeitos recebem dos verbos que os selecionam, semanticamente, o papel temático de agente \{desencadeador/controle\} .

Em suma, chegamos à conclusão de que, se o Caso ergativo se originou da reanálise de construções passivas e possessivas em muitas línguas, conforme aponta Butt (2006), não é coincidência ou casualidade que o sujeito que recebe Caso ergativo seja um sujeito agente. A proposta de que o Caso ergativo nas línguas Jê analisadas corresponde a Caso estrutural valorado pela posposição $t \varepsilon$, ganha 
força em vista da análise de Butt (2006) sobre o surgimento da ergatividade. Segundo a autora, dois fenômenos têm participação central na origem da ergatividade: a passivização e os possessivos. Com alicerce em autores como Benveniste (1952), ${ }^{9}$ Anderson (1977), ${ }^{10}$ Plank (1979), ${ }^{11}$ Garret (1990), ${ }^{12}$ Dixon (1994) $)^{13}$ e Harris \& Campell (1995), ${ }^{14}$ Butt (2002) salienta que o Caso ergativo teria surgido pela reinterpretação de um particípio da passiva como um verbo agentivo, o que, simultaneamente, também teria acarretado a reanálise do argumento agente da passiva (oblique agent adjunct) como um sujeito ergativo.

\section{Notas}

* Professor Adjunto IV da Faculdade de Letras da Universidade Federal de Minas Gerais. Bolsista de produtividade em pesquisa do CNPq-Nível 2. Email para contato: fbonfim@terra.com.br. Portal: www.letras.ufmg.br/fbonfim. Este estudo é parte de um projeto de pesquisa, intitulado Ergatividade em Línguas Indígenas e suas conseqüências para a Teoria de Caso, o qual integra um projeto maior, com o apoio do CNPq, (Processo 302674/2009-8).

**Doutoranda em Lingüística/Fale/UFMG. Email para contato: isadorabarcelos@ hotmail.com.

1 "Agree is not symmetric, but an asynmmetric, relation between a Probe and a Goal. The probe has uF features while the Goal has 'matching' iF features. Agree eliminates the uF features on the Probe by 'valuing' them and 'removing' them / 'spelling them out phonologically'. Valuing is unification of the values of the features.” (YOON, 2000, p. 4)

${ }^{2}$ Bobaljik (2006, p. 53) considera que sistemas ergativos constituem, na verdade, um epifenômeno em virtude de serem engatilhados por fatores diversos. Para o autor "ergativity may he no more a single syntactic phenomenon than is, say, verbinitialness (...)".

${ }^{3}$ Para detalhes da Cisão no sistema de caso do Apãniekra, ver a análise de ALVES, 2002; 2004.

${ }^{4}$ Conforme ALVES, 2004, p. 86: "posposições são palavras que indicam a função sintática e semântica do SN ao qual ele pertence. Pela co-relação que existe entre a ordem de constituintes e ocorrência das adposições na língua, esses marcadores de caso, como núcleos, ocorrem no final do sintagma posposicional (SP). Os nomes, que podem vir modificados por seus adjuntos, ocorrem na posição inicial de SP. Segundo a autora as principais posposições na língua Apãniekrá são: te 
ergativo; mã dativo ou benefactivo; pe malefactivo; t $\varepsilon$ genitivo; kot comitativo, to instrumental; kãm locativo; ri locativo; pe locativo; pĩn essivo, wər direcional (em movimento).

${ }^{5}$ ALVES, 2004, p. 83.

${ }^{6}$ LEGATE, J. A. Split Absolutive. In: Alana Johns, Diane Massam and Juvenal Ndayiragije. Ergativite Springer, 2006.

${ }^{7}$ CHOMSKY, N., 2004. On phases. Cambridge: MIT, ms.

${ }^{8}$ BARCELOS SILVA, 2009; 2010.

${ }^{9}$ BENVENISTE, E. La construction passive du parfait transitif. Bullétin de la Societé de Linguistique de Paris, v. 55, 1952.

${ }^{10} \mathrm{~S}$. R. On mechanisms by which Languages become Ergative. In. Mechanisms of Language Change. Austin TX: University of Texas Press. 1977, p. 317-363.

${ }^{11}$ PLANK.F. Ergativity, Syntactic Typology and Universal Grammar: some past and present viewpoints. In: Ergativity: Towards a Theory of Grammatical Relations. New York: Academic Press, 1979. p. 3-36.

${ }^{12}$ GARRET. A.. The Origin of NP Split Ergativity. Language. v. 66, p. 261-296, 1990.

${ }^{13}$ DIXON, R.M.W. Ergativity. Cambridge: Cambridge University Press, 1994.

${ }^{14}$ HARRIS. A; CAMPBELL. L. Historical Syntax in Cross-Linguistic Perspective. Cambridge: Cambridge University Press, 1995

\section{Referências}

ALVES, F. C. Aspectos da Ergatividade Cindida em Apãniekrá. Línguas Jê: estudos vários.Londrina: Ed UEL, 2002. p. 83 a 93.

ALVES, F. C. O Timbira falado pelos Canela Apãniekrá: uma contribuição aos Estudos da morfossintaxe de uma língua Jê. 177f. Tese.(Doutorado). Instituto de Estudos da Linguagem. Universidade Estadual de Campinas, Campinas, 2004.

BARCELOS SILVA, I. M. Estatuto da posposição “te” valoração de Caso ergativo e realização do papel temático em Timbira-Apãniekrá. In: BRAGGIO, Silvia Lucia Bihonjal; SOUSA FILHO, Sinval Martins de (Org.). Línguas e culturas Macro-Jê. Goiânia: Gráfica e Editora Vieira, 2009.

BOBALIK, J. D. Where's phi? Agreement as a post-syntactic operation. Connecticut: University of Connecticut, ms. 2004. 
BUTT, Miriam. Theories of case. Cambridge: Cambridge University Press, 2006. CAMPOS, C. S. O. Morfofonêmica e morfossintaxe do Maxacali, 143 f. Tese de Doutorado (em andamento). Faculdade de Letras. UFMG, Belo Horizonte, 2009.

CANÇADO, M. Posições argumentais e propriedades semânticas. DELTA, v. 21, n.1, p. 3-56, 2005.

CANÇADO, M. Argumentos: complementos e adjuntos. Alfa - Revista de Linguística, v. 53, n. 1, 2009.

DUARTE, Fábio Bonfim. Fonte de valoração do Caso ergativo e do Caso absolutivo em línguas indígenas brasileiras. Lingüística, v. 4, n. 2, p. 111-135, 2008.

DUARTE, Fábio Bonfim. A conexão entre papel Theta e Caso é sempre biunívoca? In: BRAGGIO, Silvia Lucia Bihonjal; SOUSA FILHO, Sinval Martins de (Org.). Línguas e culturas Macro-Jê. Goiânia: Gráfica e Editora Vieira, 2009.

FERREIRA, Marília. Aspectos das Classes dePalvras em Parkatêjê: uma abordagem Tipológico-Funcional. In: CABRAL, Ana Suelly Arruda Câmara Cabral; RODRIGUES, Aryon Dall'igna. Estudos sobre Línguas Indígenas. Belém: UFPA, 2001. p. 147-166.

HAIDER, Hubert. The Case of German. In: TOMAN, Jindíich (Ed.). Studies in German Grammar. Dordrecht: Foris, 1985. p. 65-101.

JÓNSSON, Jóhannes Gísli. Clausal architecture and case in Icelandic. Doctoral dissertation, University of Massachusetts, Amherst, 1996.

LEGATE, J. A. Split Absolutive In: JOHNS, Alana; MASSAM, Diane; NDAYIRAGIJE, Juvenal. Ergativity. London: Springer, 2006.

LEVIN, B. On the Nature of Ergativity. Doctoral dissertation, MIT, Cambridge, MA. (Distributed by MIT Working Papers in Linguistics; pdf available from MIT's Dspace), 1983.

LEVIN, B. The Basque verbal inventory and configurationality. In: MARÁCZ, László; MUYSKEN, Pieter (Ed.). Configurationality: The typology of asymmetries. Dordrecht: Foris, 1989. p. 39-62.

MCLEOD, Ruth; MITCHELL, Valerie. Aspectos da lingua Xavante. Brasília: SIL, 1977.

OLIVEIRA, C.O. The language of the Apinajé People of Central Brazil 430f. Tese.(Doutorado). Department of Linguistics and the Gradutate School of University of Oregon. Oregon, 2005. 
SILVA, I. M. Barcelos. Estatuto de Caso ergativo em línguas do tronco linguístico Macro-Jê: uma abordagem formal. 2010. 117 f. Dissertação (Mestrado em Estudos Linguísticos) - Faculdade de Letras da UFMG, Belo Horizonte, 2010.

WOOLFORD, E. Four-way Case Systems: Ergative, Nominative, Objective and Accusative. Natural Language and Linguistic Theory 15: p. 181-227, 1997.

WOOLFORD, E. Lexical Case, Inherent Case, and Argument Structure. MIT: Linguistic Inquiry. Cambridge: MIT Press, v. 37, n. 1, Winter 2006. 


\section{Apêndice}

\section{Abreviaturas}

ABS: Caso absolutivo; ACC: Caso acusativo; AGR: agreement (concordância número-pessoal); ASP: aspecto; AUX: verbo auxiliar; cAUs: morfema causativo; CNJ: conjunção; DAT: Caso dativo; DEF. ART.: artigo definido; DET: determinante; DEM: demonstrativo; DIR: direcional; DU: dual; ERG: Caso ergativo; FUT: futuro; GEN: genitivo; HT: termo honorífico; INCL: inclusivo; INDEF: indefinido; INFI/NF: forma verbal não-finita; IRR: irrealis; N: nome próprio; NEG: partícula de negação; NOM/ NMLZ/NZL: morfema nominalizador; PASS: passado; PD: passado distante; PL: partícula de plural; POSP: posposição; POss: prefixo que indica o possuidor; RCP: recíproco; REL: relativizador REP: repetição; REL: relativizador; RFL: reflexivo; RLS: realis; RP/PR: prefixo relacional; SG: singular; TRANs: transitividade. 